\title{
Empirical design methods in practice
}

\author{
R Pakalnis Pakalnis \& Associates and the University of British Columbia, Canada
}

\begin{abstract}
Empirical methods are the most widely used design techniques employed within the mining industry largely due to their success in the design of mine structures. This paper summarises the applications/ implementation of empirical design methods that the author has compiled/coordinated over the past thirty years with over 150 underground mining operations contributing either through consulting, research, assessment, database, verification and/or implementation. These design guidelines have been implemented throughout the world in association with researchers, mine engineers, operators and legislators to arrive at design methodologies based upon past practice and future implementation and assessment in order to ensure a safe and cost-effective mining operation. This paper summarises design curves that have been developed at the University of British Columbia over the past thirty years with the methodology for design being a common thread for all the tools presented which requires the operator to address stress, structure and the rock mass.
\end{abstract}

\section{Introduction}

Mining is a dynamic process, which requires in excess of thousands of cubic metres of openings to be developed daily over the life of a mining operation. Those openings may be for development and/or production purposes; however, all cases must be designed so as to ensure the required behaviour. The site engineer, therefore, must design openings or pillars after addressing all issues relevant to the design and assessment of the overall behaviour.

A mine structure, whether it is a mine pillar or an opening, is generally influenced by numerous blocks of intact rock. Individually their properties and behaviour can be readily assessed on a laboratory scale; however, when analysed on a mine wide scale, the interaction of the rock block and the rock mass behaviour is difficult if not impossible to predict employing solely a deterministic approach.

Design can be categorised into three domains:

- Analytical methods in the form of numerical codes, closed form solutions, classical physical and strength models.

- Observational methods which rely on monitoring of the rock mass and verification of behaviour.

- Empirical methods which assess the stability based upon past practice coupled with existing mine behaviour for future prediction.

Empirical derivations have gained acceptance over the last thirty years largely due to their predictive capability since conventional methods of assessment have the difficulty of identifying the jointed nature of the rock material, assigning properties thereto and establishing input parameters for subsequent numerical evaluation. The process that the author has found to be of greatest value is to employ numerical codes, analytical tools and observational approaches as tools to the overall design process which will incorporate an empirical component towards the design. Individually each is only a tool that requires the designer to address the factors most critical to the stability of the overall underground structure which includes stress, structure and the rock mass as (Figure 1). The field of empirical mine design can be broken into the broad categories of pillar design and opening design. Opening design has evolved from the tunnel span design methods of the 1960s and 1970s (Bieniawski 1976). Underground openings have more complex geometries than found in tunnels, which has required different design approaches. Some of the first 
applied empirical mine design methods for openings originated with the work of Mathews et al. (1980) and Laubscher (1977). Applied pillar design work has developed from early coal mining with applied design curves developed by Lunder (1994) and used internationally. Extensive work in areas of drift and stope openings and pillar design have been conducted in Australia and Canada with some of the most widely applied methods originating at the University of British Columbia, Canada (Mathews et al. 1980; Lang 1994; Potvin 1988; Nickson 1992). The more widespread use of empirical methods inherently made these systems more reliable since they are developed and refined only through use and experience with verification through measurement with inputs from analytical sources coupled with stress, structure and the rock mass as inputs. Empirical design methods are evolving and the application of some of these methods is becoming confusing. The methods are being modified and used within new ground conditions and mining environments, sometimes without regard to the original conditions that the design methods were developed for. It is critical to know thy database as empirical design must interpolate between known conditions and not extrapolate beyond the database. In addition, researchers' potentially add levels of complexity to the empirical design methods that are sometimes unwarranted and unnecessarily confusing.

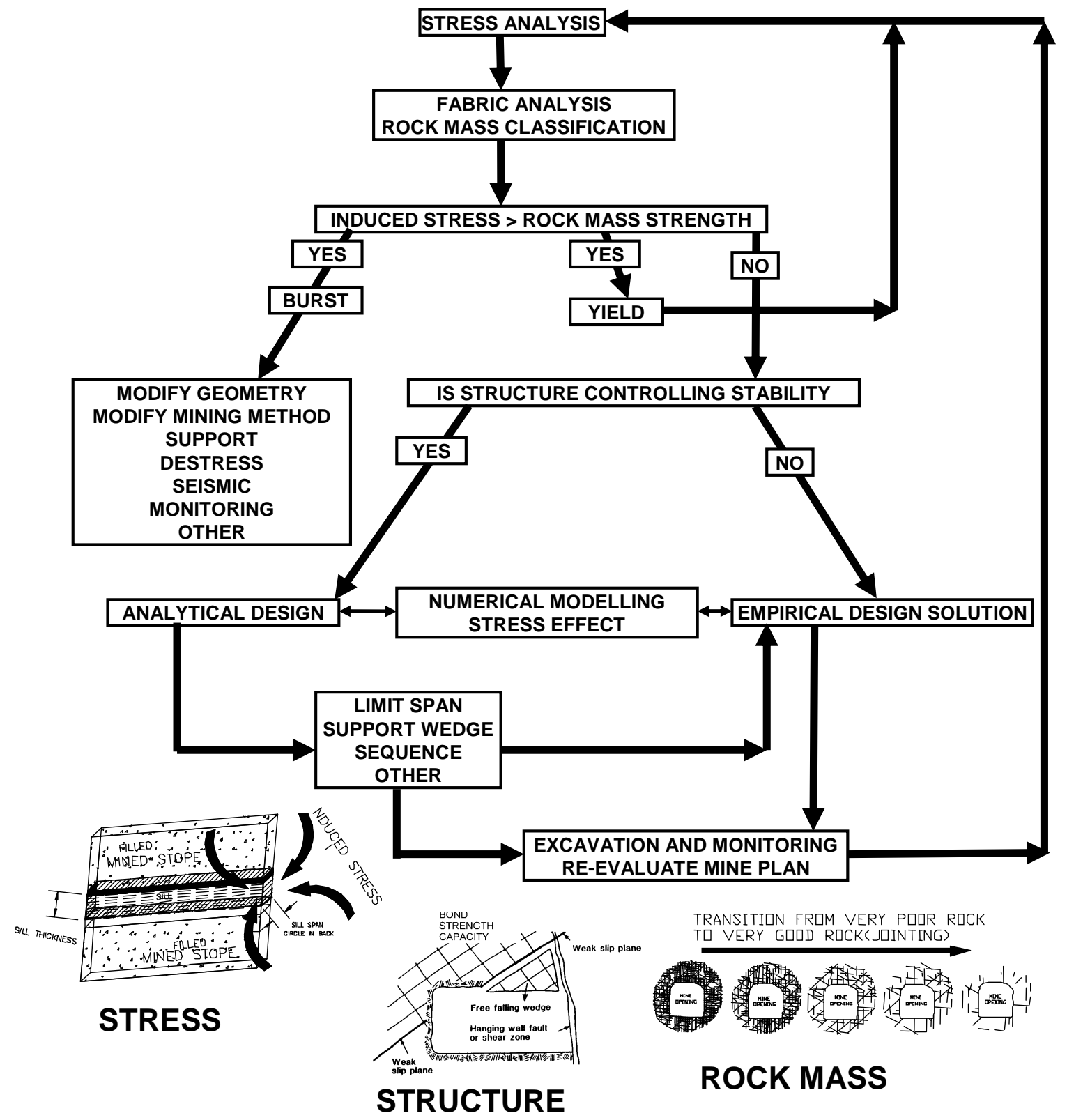

Figure 1 Design methodology incorporating stress, structure and the rock mass 
The design methods summarised in this paper are based upon a strong analytical foundation coupled with extensive field observation to arrive at a calibrated empirical approach towards the solution to a given problem. The methods presented in this paper are compiled from extensive mine visits, literature reviews, discussions among researchers and practitioners coupled with analytical and numerical assessments with the successful implementation at mine operations. Two prime objectives inherent with the design process are that the mine must be safe and operate as economically as possible. This paper reviews updates to the design curves presented in Pakalnis (2002) with subsequent implementation and observation with respect to their use as design tools for the mining industry.

\section{Design relationships}

The reader is referred to an earlier paper (Pakalnis 2002) on the details of the individual design curves presented in this paper as the focus here is on the modifications and subsequent use of the proposed relationships over the past thirty years.

\subsection{Stability graph method - ELOS}

The stability graph method for open stope design was initially proposed by Mathews et al. (1980) and subsequently modified by Potvin (1988) and Nickson (1992) to arrive at the modified stability graph. Stability was qualitatively assessed as either being stable, potentially unstable or caved. Research at the University of British Columbia quantified the degree of slough by the introduction of the term 'equivalent linear overbreak/slough' (ELOS) by Clark (1998). This has resulted in the empirical estimation of wall slough employing the stability number $\mathrm{N}^{\prime}$, as shown in Figure 2, with respect to the hydraulic radius.

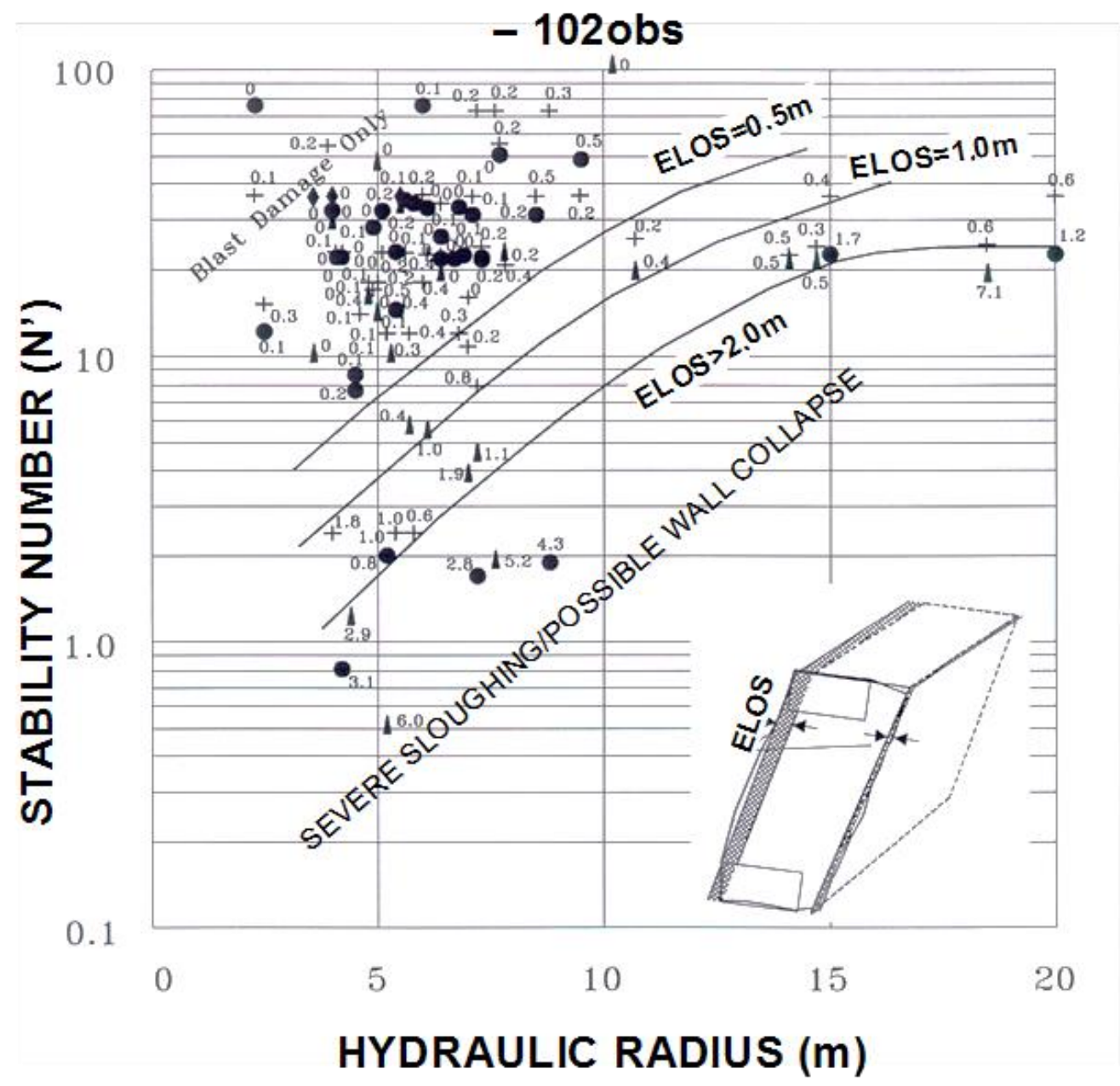

Figure 2 Empirical estimation of wall slough (ELOS) after Clark (1988) 


\subsection{Span design - entry methods}

The critical span curve (Lang 1994) has been augmented to include 292 case histories of stable and unstable entry-type stope backs from six different mines by Wang et al. (2000). It expands on the original database to incorporate lower rock mass ratings (RMRs) (Figure 3). The critical span is defined as the diameter of the largest circle that can be drawn within the boundaries of the exposed back, as viewed in plan and shown in Figure 3. This exposed span is then related to the prevailing rock mass of the immediate back to arrive at a stability condition. The design span refers to spans which have used no support and/or spans which include pattern bolting $(1.8 \mathrm{~m}$ long bolts on $1.2 \times 1.2 \mathrm{~m})$ for local support. The RMR, as proposed by Bieniawski (1976), is employed with corrections for the presence of shallow joints (under $30^{\circ}$ ) by reducing the RMR by ' 10 '. The stability of the excavation is classified into three categories:

- Stable excavation

- No uncontrolled falls of ground.

○ No movement of back observed.

○ No extraordinary support measures have been implemented.

- Potentially unstable excavation

- Extra ground support may have been installed to prevent potential falls of ground.

○ Movement within back.

- Increased frequency of ground working.

- Unstable excavation

- The area has collapsed.

- Failure above the back is approximately 0.5 times span in the absence of major structure.

- Support was not effective to maintain stability.

\section{Updated Span Design Curve}

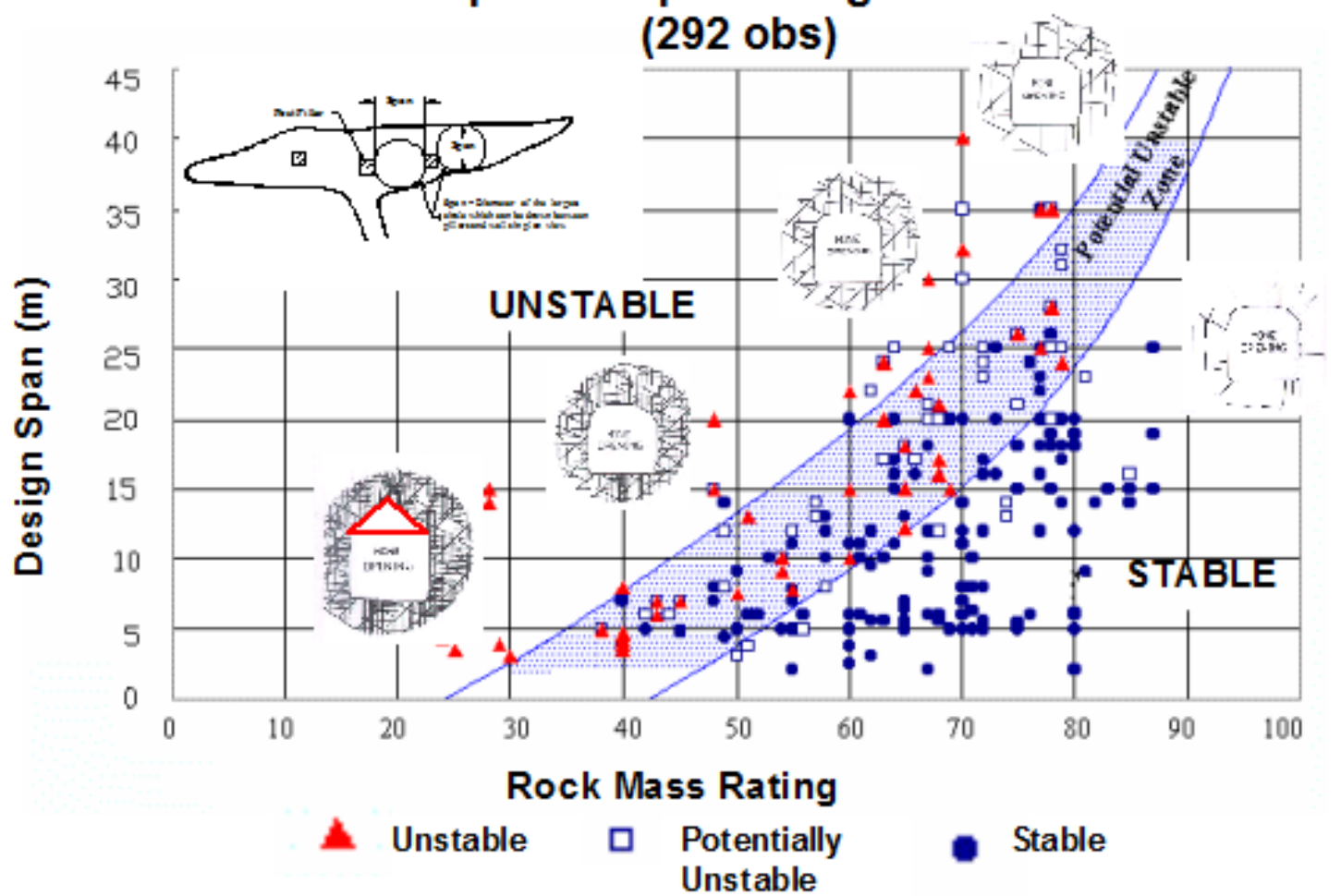

Figure 3 Critical span curve for mine entry methods employing local support only 
The above approach is based upon rock mass instability. Where discrete wedges have been identified, they must be supported prior to assessment employing the critical span curve. Stability is generally identified in terms of short term stability (excess of three months) as the database is largely based upon stoping methods that are of short duration. Where back movement has been identified, critical magnitudes in excess of $1 \mathrm{~mm}$ within a twenty-four hour period dictate that the stope will not be accessed for a further twenty-four hour period. This is based upon observations from the six mines comprising the database.

\subsection{Pillar design graph}

A comprehensive pillar database that relates geometry, loading conditions, in situ rock strength and stability condition has been developed. Analysis of this database has led to the development of the pillar stability graph (Figure 4).

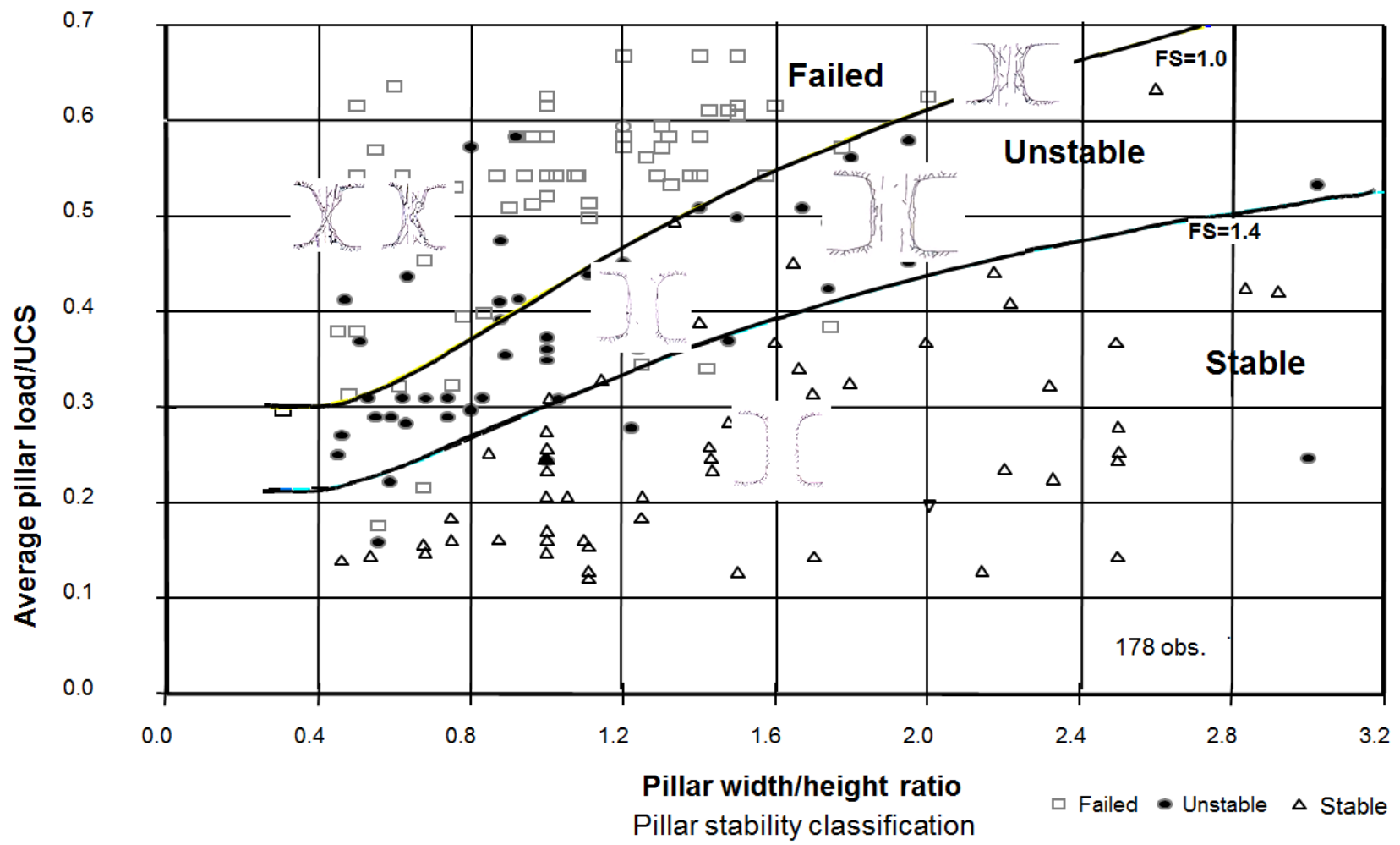

Figure 4 Pillar stability graph

A total of 178 stability cases have been included where each case example represents a failed pillar, an unstable pillar or a stable pillar, as compiled by Lunder (1994). The pillar data used to develop this methodology is a compilation of seven individual pillar stability databases that have been published worldwide. The information available is the pillar stability assessment, the predicted pillar load and the pillar geometry. Five of the seven databases originate from massive sulphide deposits and all of the databases have reported RMRs in excess of $65 \%$, representing good to very good quality rock mass conditions. Figure 4 shows the observed conditions that would be encountered for each stability level. This is based upon detailed research work showing that pillar stability levels could be assessed on a five level scale. This was simplified in order to assimilate the data with the additional databases that were collected from the literature. Two primary factors are used in this design methodology: a geometric term that represents pillar shape and a strength term that includes the intact rock strength and the predicted pillar load. Rock mass strength is dependent upon the amount of confining stress applied to a sample. In the case of mine pillars, the more slender a pillar, the less confining stress will be available resulting in a lower strength for a given rock type. The pillar width $(\mathrm{Wp})$ is defined as the dimension normal to the direction of the induced stress, whereas the pillar height $(\mathrm{Hp})$ is measured parallel to the induced stress. The pillar strength graph was developed by plotting the ratio of pillar load/unconfined compressive strength (UCS), as 
shown in Figure 4 to the $\mathrm{Wp} / \mathrm{Hp}$. The pillar load is measured at the core of the pillar whereas the UCS is that recorded for the intact rock comprising the pillar. The pillar stability graph presented here is a collection of a wide range and type of mine pillar.

\section{Support design}

The reader is referred to an earlier paper by Pakalnis (2008) on the details of the methodology towards support that has been derived from over twenty mining operations that incorporate analytical and empirical approaches towards assessing the Factor of Safety (FS) for a mine opening. The approach is to assess the potential for an adverse structure employing an analytical approach, such as provided by the software program Unwedge (Rocscience 2008). The initial assessment as practised at the face is to define if a dead-weight wedge is possible and this employs a simple stereo analysis pole plot (Figure 5). This figure shows conditions for gravity falls and how it is presented onto a stereographic projection. The plot of great circles representing the individual planes must encompass the centre in order for a gravity fall to occur, whereas for a sliding wedge, this does not occur. Similarly, the pole plot shows that a triangle drawn between the three poles must encompass the centre in order to have a gravity fall.
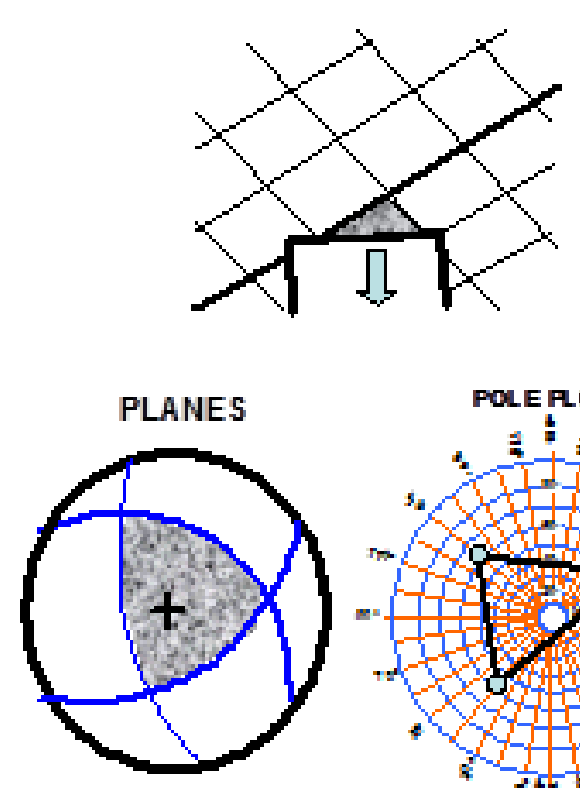

A) GRAVITY FALL

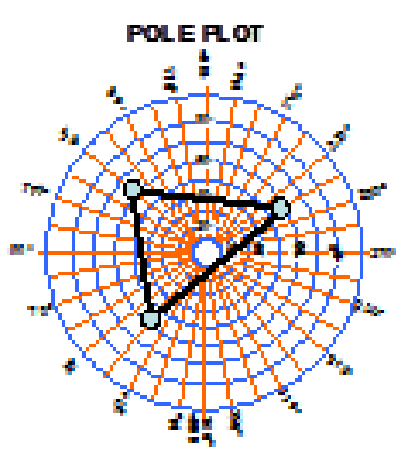

Figure 5 Conditions for (a) gravity fall and (b) sliding instability for wedge within back of tunnel
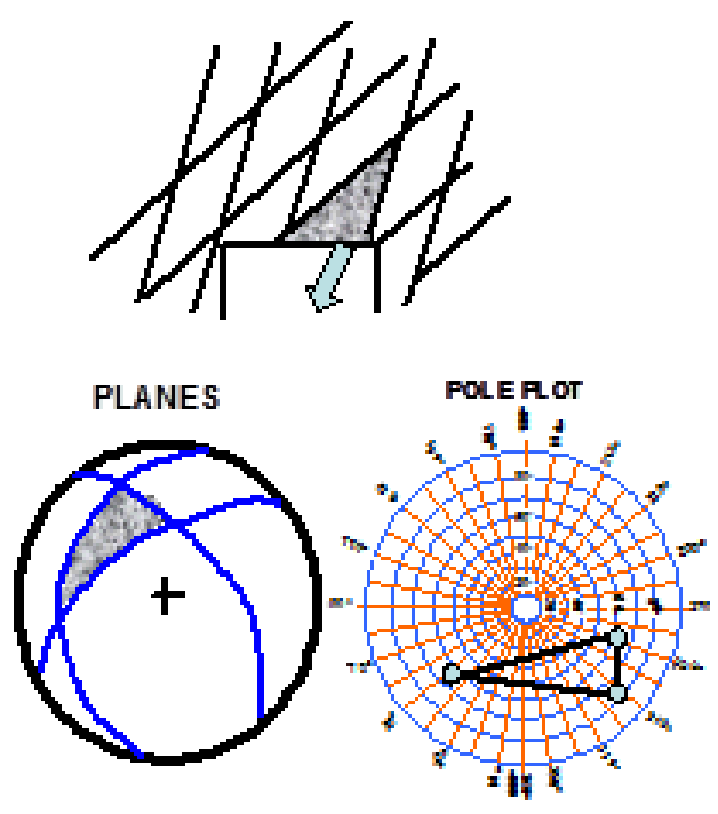

B) SLIDING WEDGE

\subsection{Dead weight}

Dead weight conditions if identified structurally by the above test (Figure 5) would conservatively estimate that the maximum depth of failure would be 0.5 times the span. Typically, a depth of failure equivalent to either 0.5 to 0.3 times span is employed in practise (Beauchamp 2006); however, based upon past observed back failures and modelling (MacLaughlin et al. 2005), one largely observed an arched back, as shown in Figure 6. It must be noted that the depth of failure is assumed to be $0.5 \times$ span; however, with adverse structure present one must assess analytically (i.e. Unwedge) the volume of the wedge to arrive at the true volume which will generally be less than 0.5 times span. The potential failure zone is then approximated (Figure 6) with the bolt capacity, as defined by the breaking strength of the bolt as well as the bond strength of the bolt passing though the failure surface (Tables 1-3). The above approach assumes all bolts are plated with the support capacity defined by the value of the sum of the individual bolts, which are defined by either the breaking strength or the bond strength of the bolts passing through the failure surface - whichever is the lower of the two. The above is a conservative approach, as the analysis assumes a centre bolt at mid span. The potential for structural instability was identified as dead weight; however, a 
detailed analytical assessment such as provided by Unwedge will result in a more realistic and less conservative assessment, as the depth of failure is most likely much less than 0.5 times span but has to be identified in the field as having this potential. A further constraint is that the corner bolt should be in excess of 0.5 times bolt spacing from the adjacent wall in order to ensure effectiveness unless strapped/shotcreted.

\section{"DEAD WEIGHT ANALYSIS: WEDGE HEIGHT $=0.5 \times$ SPAN}

\section{SUPPORT PATTERN: 2.4m LONG \#6 REBAR ON 1m X 1m PATTERN}

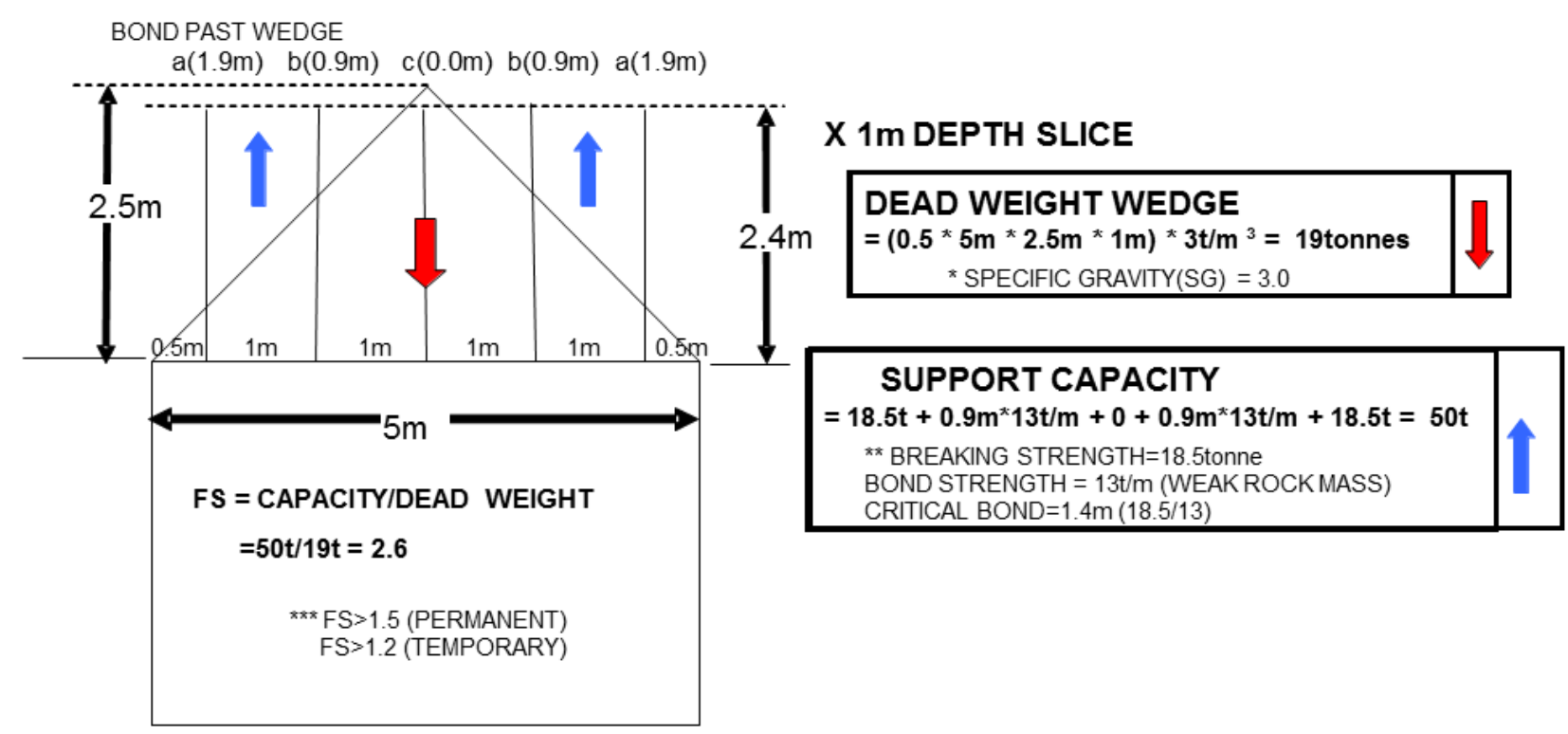

Figure 6 Factor of Safety analysis dead weight

\subsection{Rock mass assessment}

The potential for rock mass instability is defined by the span design curve, which employs local/no support, as shown in Figure 3 and detailed by Pakalnis et al. (2007). The depth of failure has been observed in the absence of structural instability to be equal to 0.5 times span for the 'unstable' zone and approaching from '0-0.5' times the span within 'the potentially unstable zone'.

\subsection{Surface support}

This is detailed in Pakalnis et al. (2010) and summarised in this paper where the use of shotcrete as confining the rock mass fabric into a single support unit is assessed (Figure 8). It must be recognised that a weak rock mass will likely result in the individual rock blocks falling between the bolts; therefore, surface support is required to confine the rock mass as a single support unit. It is also critical to bolt through the shotcrete membrane within a weak rock mass $\left(\mathrm{RMR}_{76} \leq 45 \%\right)$ to ensure that the bolts and surface support are confined and do not act independently of each other. Surface support requirements for temporary and permanent (storage rooms, crusher chambers and maintenance shops) support correspond to an excavation support ratio (ESR) of 3 and 1.3, respectively (Grimstad \& Barton 1993). This is shown in Figure 8 with the range of weak rock masses observed within Nevada operations (20-45\%) and associated spans of $6 \mathrm{~m}(20 \mathrm{ft})$ and summarised in Table 4 . It must be recognised that the shotcrete is reinforced with bolts which confine the potential block. 


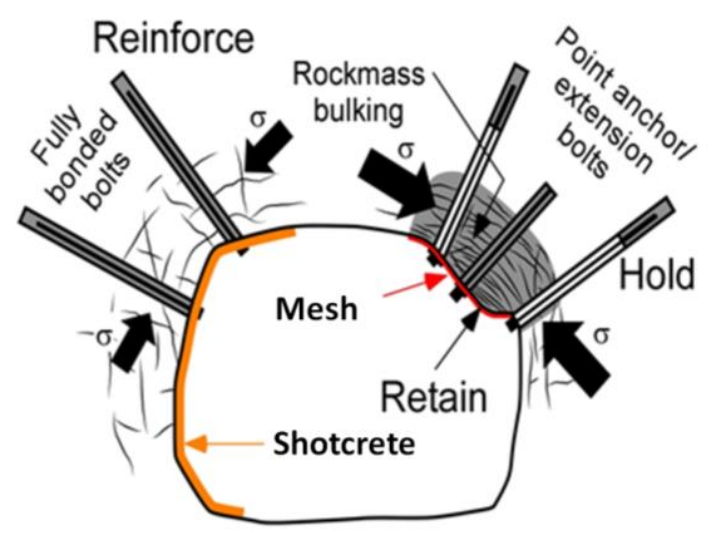

Figure 7 Shotcrete as confining the rock mass into a single unit

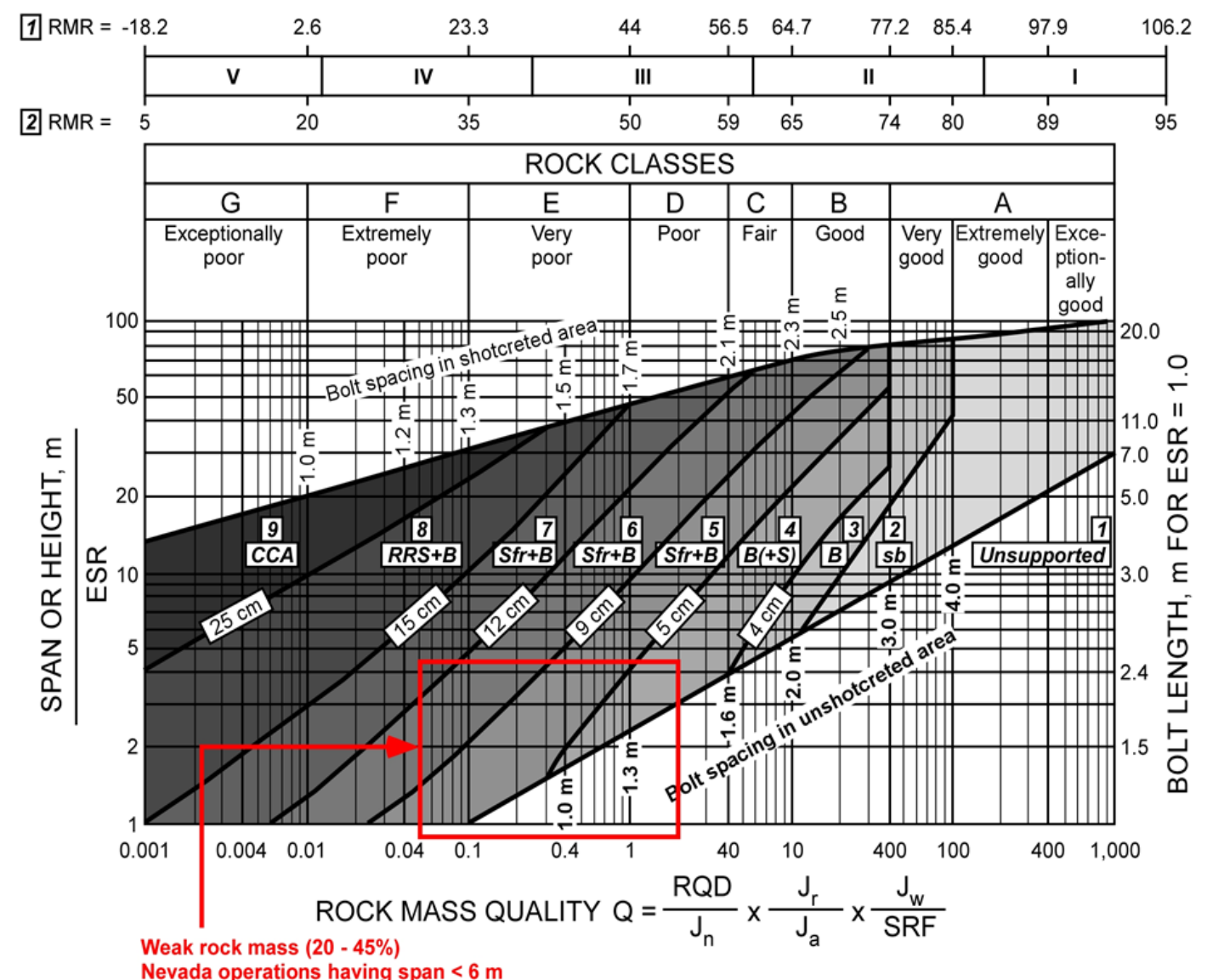

Nevada operations having span $<6 \mathrm{~m}$

Reinforcement categories
1 Unsupported
2 Spot bolting, sb
3 Systematic bolting, B
4 Systematic bolting and unreinforced shotcrete, $4-10 \mathrm{~cm}, \mathrm{~B}(+\mathbf{S})$
5 Fiber reinforced shotcrete and bolting, $5-9 \mathrm{~cm}, \mathrm{Sfr}+\mathrm{B}$
6 Fiber reinforced shotcrete and bolting, $9-12 \mathrm{~cm}, \mathrm{Sfr}+\mathrm{B}$
7 Fiber reinforced shotcrete and bolting, $12-15 \mathrm{~cm}, \mathrm{Sfr}+\mathrm{B}$
8 Fiber reinforced shotcrete $>15 \mathrm{~cm}$ and reinforced ribs of shotcrete and bolting, Sfr+RRS+B

9 Cast concrete lining, CCA

Excavation categories
A Temporary mine openings
B Permanent mine openings, water tunnels for hydro power (excluding high pressure penstocks), pilot tunnels, drifts and headings for large excavations
C Storage rooms, water treatment plants, minor road and railway tunnels, surge chambers, access tunnels 1.3
D Power stations, major road and railway tunnels, civil defense chambers, portal intersections 1.0
E Underground nuclear power stations, railway stations, sports and public facilities, factories

Figure 8 Surface support (after Grimstad \& Barton 1993) 


\subsection{Intersection support}

Intersection support as shown in Figure 9 employs the methodology outlined in this section in terms of dead weight support and surface support (Figure 9). The volume of failure is approximated by a right angle cone having a height equal to 0.5 times diameter with support capacity defined by the value of the sum of the individual bolts which are defined by either the breaking strength or the bond strength of the bolts passing through the failure surface - whichever is the lower of the two. The above is a conservative approach as the analysis assumes a centre bolt at mid span. The potential for structural instability was identified as dead weight; however, a detailed analytical assessment such as provided by Unwedge will result in a more realistic and less conservative assessment as the depth of failure is most likely much less than 0.5 times span but has to be identified in the field as to this potential. A further constraint is that the bolt past the cone boundary must be greater than $0.5 \times$ bolt spacing since one would largely negate the support capability with having a corner bolt unless confined by straps/shotcrete.

\section{INTERSECTION SUPPORT DESIGN}

CONE WITH BASE EQUAL TO DIAMETER (D) OF INTERSECTION. HEIGHT OF FAILURE $(H)=0.5 \mathrm{X}$ DIAMETER.

\section{le. $20 \mathrm{~m}$ DIAMETER (D) CONE-10m HT (H)}
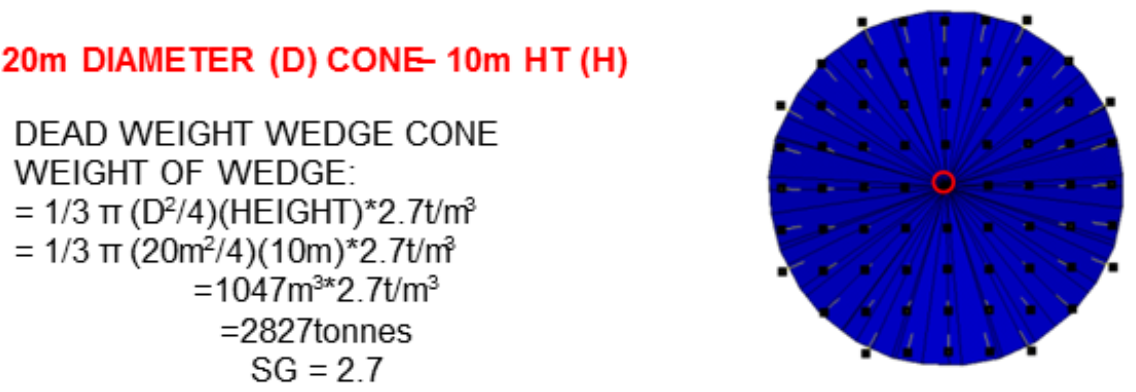

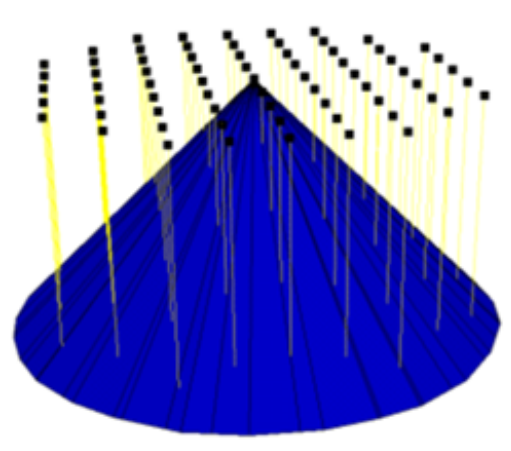

With $10 \mathrm{~m} 2 \times$ cable bolts on $2 \mathrm{~m} \times 2 \mathrm{~m}$ pattern: -Strength $=40 \mathrm{t}$ -Bond $=20 \mathrm{t} / \mathrm{m}$ -Critical bond length: $2 \mathrm{~m}$

Figure 9 Intersection support dead weight
CRITERIA: A) BOND STRENGTH PAST CONE + B) BOLT PAST CONE BOUNDARY >0.5 X BOLT SPACING le. $10 \mathrm{~m}$ LONG $2 \mathrm{X}$ CABLE BOLTS ON $2 \mathrm{~m}$ X $2 \mathrm{~m}$ PATTERN.

\author{
Om past wedge \\ (rest are $>2 \mathrm{~m}$ ) \\ Cables $>1 \mathrm{~m}$ from boundary of cone. \\ Support strength: \\ $(68$ cables $* 40 t /$ cable $)=2720 \mathrm{t}$
}

$\mathrm{FS}=2720 \mathrm{t} / 2827 \mathrm{t}=1.0+$ STD SUPPORT COMPRISED OF $2.4 \mathrm{~m}$ LONG \#6 REBAR ON $1.2 \mathrm{~m} \times 1.2 \mathrm{~m}$ PATTERN. 
Table 1 Support properties - rockbolt properties

\begin{tabular}{lcc}
\hline \multicolumn{1}{c}{ Bolt type } & Yield strength (tonnes) & Breaking strength (tonnes) \\
\hline 15.9 mm (5/8") mechanical & 6.1 & 10.2 (grade 690 MPa) \\
Split set (SS-33) & 8.5 & 10.6 \\
Split set (SS-39) & 12.7 & 14 \\
Standard Swellex & $n / a$ & 11 \\
Yielding Swellex & $n / a$ & 9.5 \\
Super Swellex & $n / a$ & 22 \\
20 mm rebar (\#6) & 12.4 & 18.5 \\
22 mm rebar (\#7) & 16 & 23 \\
25 mm rebar (\#8) & 20.5 & 30.8 \\
\#6 DYWIDAG & 11.9 & 18 \\
\#7 DYWIDAG & 16.3 & 24.5 \\
\#8 DYWIDAG & 21.5 & 32.3 \\
\#9 DYWIDAG & 27.2 & 40.9 \\
\#10 DYWIDAG & 34.6 & 52 \\
12.7 mm (1/2") cable bolt & 15.9 & 18.8 \\
15.9 mm (5/8") cable bolt & 21.6 & 25.5 \\
$6.35 \times 102$ mm (1/4 × 4") strap (MS) & 25 & 39 \\
\hline
\end{tabular}

$\# 6$ refers to $6 / 8$ "; \#7 refers to $7 / 8$ " diameter etc.

Table 2 Support properties - Screen-bag strength $1.22 \times 1.22 \mathrm{~m}(4 \times 4 \mathrm{ft})$ pattern

\begin{tabular}{ll}
$102 \times 102 \mathrm{~mm}\left(4 \times 4^{\prime \prime}\right)$ wielded wire mesh (4 gauge) & Bag strength $=3.6$ tonnes \\
$102 \times 102 \mathrm{~mm}\left(4 \times 4^{\prime \prime}\right)$ wielded wire mesh (6 gauge) & Bag strength $=3.3$ tonnes \\
$102 \times 102 \mathrm{~mm}\left(4 \times 4^{\prime \prime}\right)$ wielded wire mesh (9 gauge) & Bag strength $=1.9$ tonnes \\
$102 \times 50.8 \mathrm{~mm}\left(4 \times 2^{\prime \prime}\right)$ wielded wire mesh (12 gauge) & Bag strength $=1.4$ tonnes \\
$50.8 \mathrm{~mm}\left(2^{\prime \prime}\right)$ chainlink (11 gauge bare metal) & Bag strength $=2.9$ tonnes \\
$50.8 \mathrm{~mm}\left(2^{\prime \prime}\right)$ chainlink (11 gauge galvanised) & Bag strength $=1.7$ tonnes \\
$50.8 \mathrm{~mm}\left(2^{\prime \prime}\right)$ chainlink (9 gauge bare metal) & Bag strength $=3.7$ tonnes \\
$50.8 \mathrm{~mm}\left(2^{\prime \prime}\right)$ chainlink (9 gauge galvanised) & Bag strength $=3.2$ tonnes \\
\hline
\end{tabular}

4 gauge $=584 \mathrm{~mm}\left(23^{\prime \prime}\right)$ diameter; 6 gauge $=5.08 \mathrm{~mm}\left(0.20^{\prime \prime}\right) ; 9$ gauge $=4.06 \mathrm{~mm}\left(0.16^{\prime \prime}\right)$ diameter; 11 gauge $=3.18 \mathrm{~mm}\left(0.125^{\prime \prime}\right)$; 12 gauge $=2.79 \mathrm{~mm}\left(0.11^{\prime \prime}\right)$ diameter.

Shotcrete shear strength $=2 \mathrm{MPa}=200$ tonnes $/ \mathrm{m}^{2}$. 
Table 3 Support properties - bond strength

\begin{tabular}{lc}
\hline \multicolumn{1}{c}{ Bolt type } & Bond strength (tonnes $/ \mathrm{m}$ ) \\
\hline $39 \mathrm{~mm}$ split set weak ground (<45\% RMR) & $0.75-3.6$ \\
$39 \mathrm{~mm}$ split set hard ground (>55\% RMR) & $2.5-5$ \\
Standard Swellex weak ground (<45\% RMR) & $8.1-13.8$ \\
Standard Swellex hard ground (>55\% RMR) & $9-15$ \\
Cable bolt weak ground (<45\% RMR) & 24 \\
Cable bolt hard ground ( $>55 \% \mathrm{RMR})$ & 28 \\
$\# 6$ rebar weak ground (<45\% RMR) & $12-14$ \\
\#6 rebar hard ground (>55\% RMR) & 59 \\
\hline
\end{tabular}

Table 4 Fabric support requirements (after Grimstad \& Barton 1993) for $6 \mathrm{~m}$ span

\begin{tabular}{cccc}
\hline Q & RMR & $\begin{array}{c}\text { Permanent support } \\
\text { ESR }=1.3\end{array}$ & $\begin{array}{c}\text { Temporary support } \\
\text { ESR }=\mathbf{3}\end{array}$ \\
\hline 0.07 & $<20 \%$ & Spiling + (actual) & Spiling + (actual) \\
$0.07-0.4$ & $20-35 \%$ & $9-12 \mathrm{~cm}\left(3-5^{\prime \prime}\right)$ & $5-9 \mathrm{~cm}\left(2-4^{\prime \prime}\right)$ \\
& & fibre-reinforced shotcrete & fibre-reinforced shotcrete \\
$0.4-1.1$ & $35-45 \%$ & $\begin{array}{c}5-9 \mathrm{~cm}\left(2-4^{\prime \prime}\right) \\
\text { fibre-reinforced shotcrete }\end{array}$ & $\begin{array}{c}4-10 \mathrm{~cm}\left(2-4^{\prime \prime}\right) \\
\text { fibre-reinforced shotcrete }\end{array}$ \\
\hline
\end{tabular}

\section{$4 \quad$ Weak rock mass design}

A major study was undertaken by the US National Institute for Occupational Safety and Health (NIOSH) and detailed in Brady et al. (2005) to address the high frequency of roof-fall injuries being recorded in Nevada mines. The Spokane Research Laboratory and the University of British Columbia Geomechanics group focused on the development of safe and cost-effective underground design guidelines for weak rock masses having an RMR in the range of 15 to $45 \%$. Figure 10 shows the existing empirical database prior to the study where the rock masses were largely classified in excess of $65 \%$ (RMR $\mathrm{R}_{76}$ ). A weak rock mass upon review of site conditions observed was presented as that having an $\mathrm{RMR}_{76}$ of less than $45 \%$ and/or a rock mass quality ( $\mathrm{Q}$ ) of under 1.0. This is based upon a database in excess of twenty mining operations, as detailed in Pakalnis et al. (2007). Weak ground conditions, ground support, and mining methods used in several Nevada underground mines were observed. The RMR values were calculated to update both span design calculations and stability graphs, and a database on underhand mining methods was developed to reflect existing Nevada mining conditions. The immediate rock mass was also characterised and analysed in terms of prevailing type of ground support, potential failure mechanisms, and rock behaviour which resulted in modifications/augmentation to the design curves, as shown in Figure 11, for the wall stability graph for weak rock masses. An initial observation from Figure 11 is that the classical design curves (ELOS), as shown in Figure 2, are inaccurate at low $\mathrm{N}^{\prime}$ and hydraulic radius values. If the hydraulic radius is kept below $3.5 \mathrm{~m}$ within a weak rock mass, the ELOS value was recorded to be less than $1 \mathrm{~m}$. 


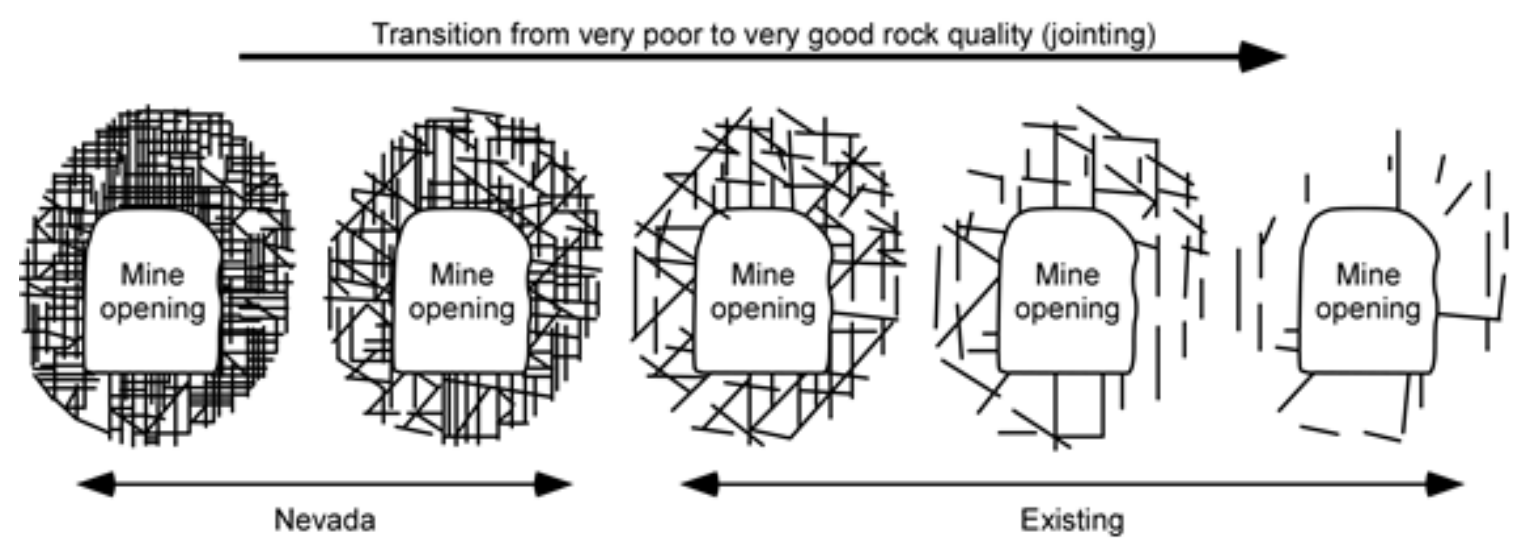

Figure 10 Schematic showing transition of weak rock mass to stronger along with existing database

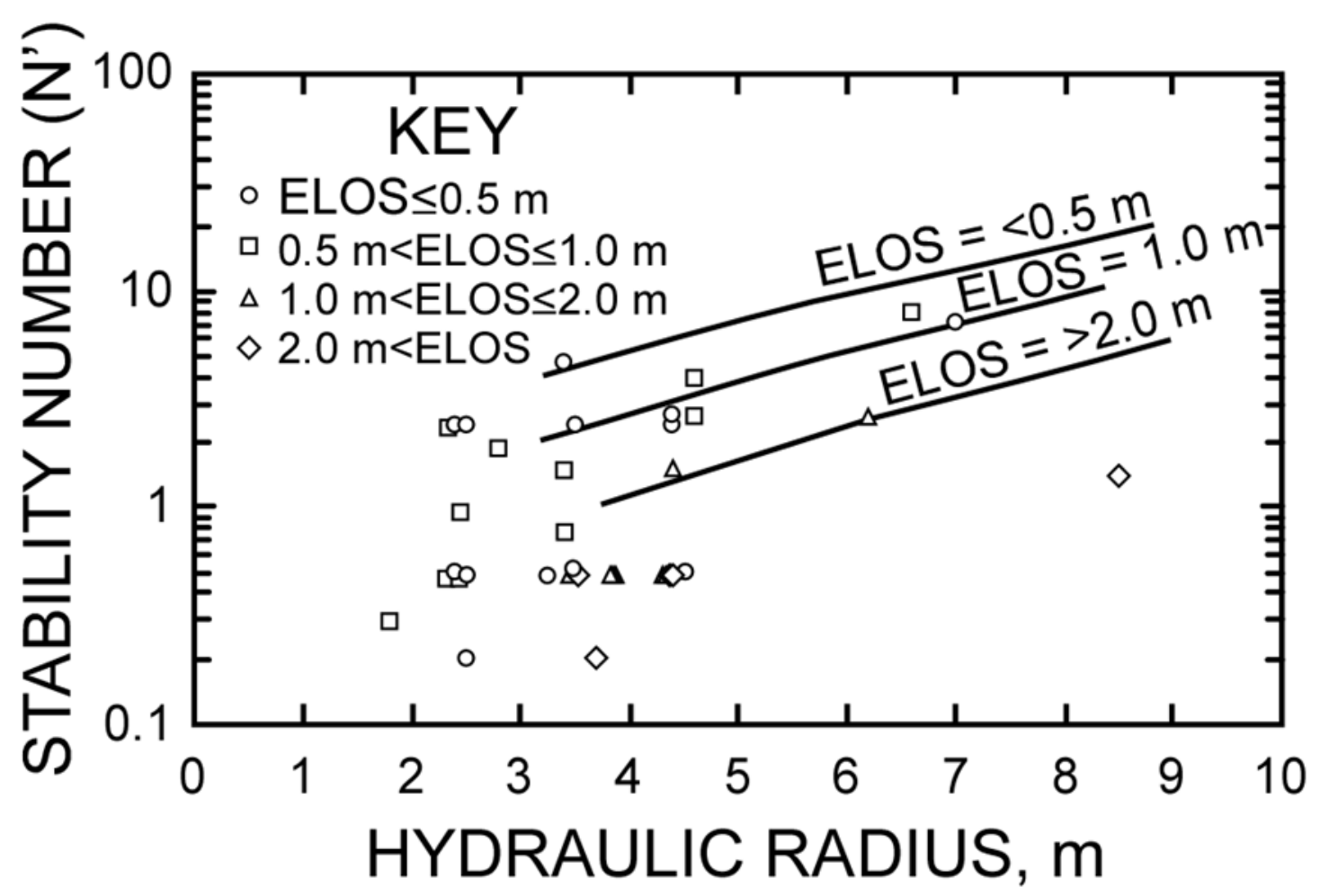

Figure 11 Wall stability graph as developed for weak rock masses (Pakalnis et al. 2007)

\subsection{Operations guidelines}

With weak rock masses, blast control is critical to ensure that the rock mass is not further disturbed from over blasting. Both Queenstake's SSX Mine and Barrick's Goldstrike operation guidelines for blasting based on RMR values have been summarised in Figure 12. In addition, the length of round pulled is related to the RMR for a 5 m supported back span (Figure 12). An example is where the RMR is $15-20 \%$. This would dictate that only a $1.2 \mathrm{~m}$ advance is possible otherwise failure of the unsupported back will result. Spiling is recommended at these RMR thresholds. Figure 12 shows the degree of loading of a development round at Barrick's Goldstrike Mine for a $5 \times 5 \mathrm{~m}$ heading with respect to the RMR. 


\section{SSX MINE - QUEENSTAKE/NEVADA (ELKO)}

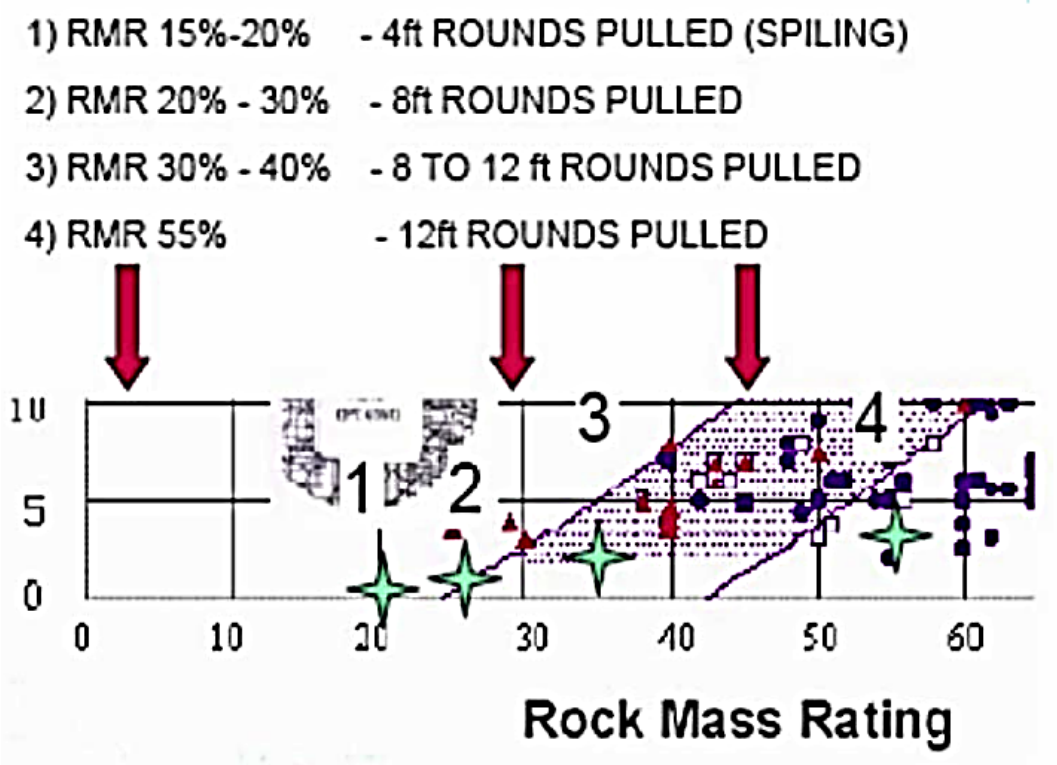

\begin{tabular}{|l|}
\hline \multicolumn{1}{|c|}{ BARRICK GOLDSTRIKE } \\
\hline RMR $45 \%$ LOAD FULL FACE (5m X 5m) 115kg-160kg EXPLOSIVE \\
\hline RMR 25\%-45\% LOAD HALF FACE LOADED 40kg EXPLOSIVE AND UNDER \\
\hline RMR $25 \%$ LIFTERS ONLY LOADED - OR FREE DIGMUCK \\
\hline TYPICAL ADVANCE IS 1.5 to 2.8m DEPENDING UPON RMR \\
\hline
\end{tabular}

Figure 12 RMR versus influence on blasting in weak ground (Pakalnis et al. 2007)

The effect of blasting on weak rock masses was further assessed through a NIOSH sponsored initiative and detailed by Caceres (2011) in his PhD dissertation: 'Quantifying the Effect of rock mass quality on peak particle velocity (PPV) for underground drift development'. Figure 13 shows a relationship derived from the PPV and scaled distance (SD) as a function of rock mass quality obtained from multiple records and operations to arrive at critical thresholds for blast design. 


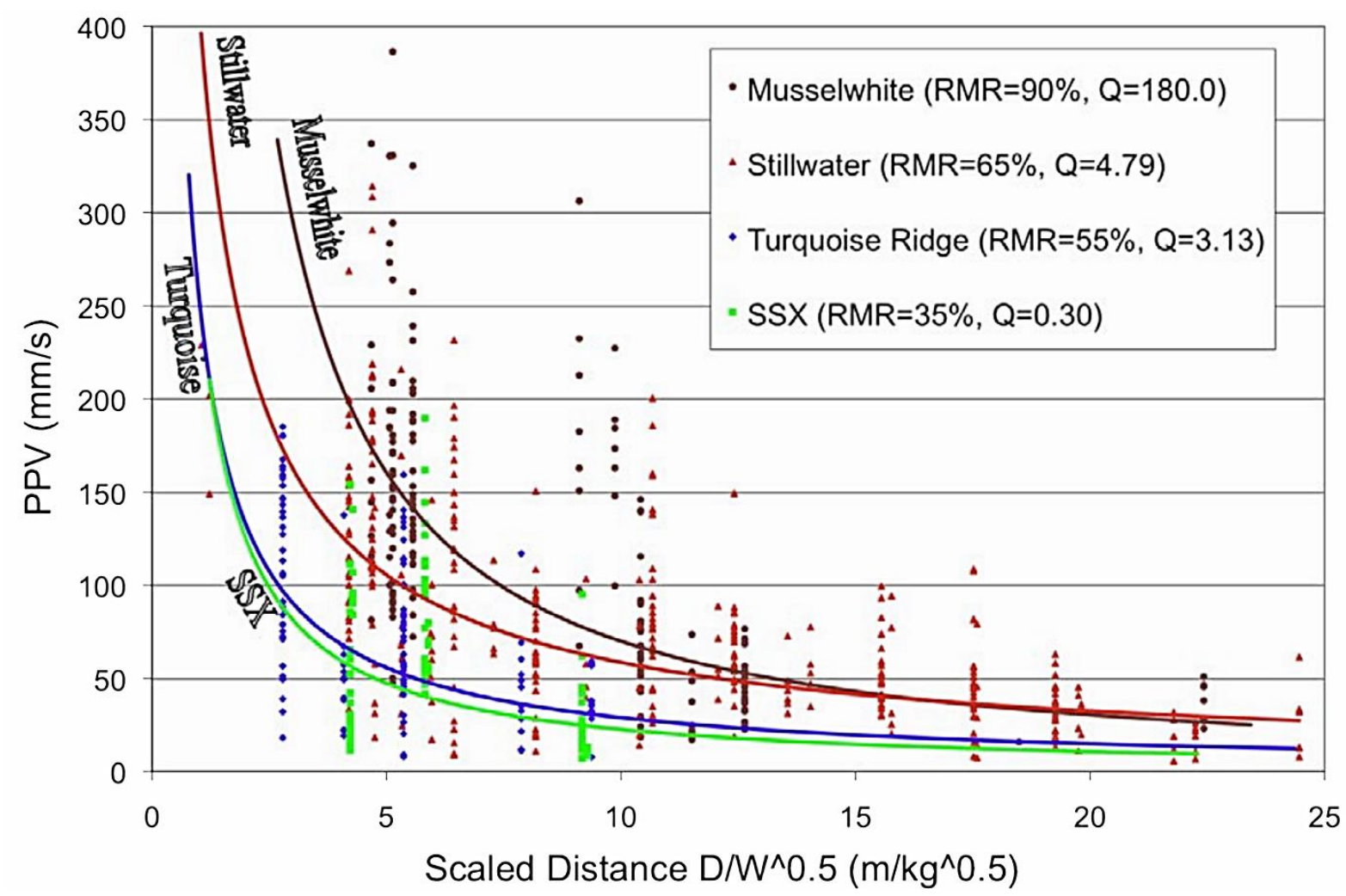

Figure 13 PPV versus scaled distance for varying rock qualities

A further observation amongst weak rock mass mines was the success achieved through arching of the back. It was found that for weak rock masses that arching the back dramatically increased the overall stability for a given span. This is schematically shown in Figure 14 whereby the potential wedge volume is significantly decreased employing an arched back and the effectiveness of the applied support increased as a greater length of bolt passes beyond the failure plane. This has been shown to be a major contributing factor to the overall stability for mines operating within weak rock masses.
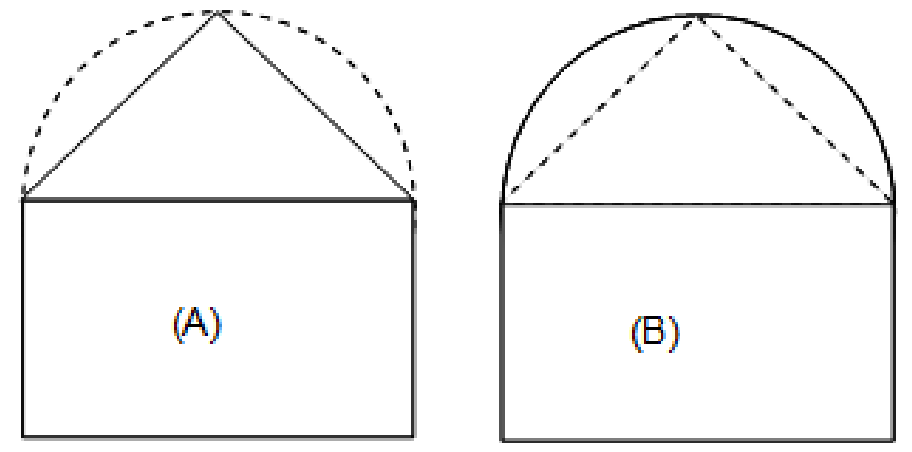

Figure 14 Effect of arching on back of tunnel

\section{Other observations}

This section refers to empirical approaches developed with UBC researchers and industry sponsors to address problems that assisted in understanding the overall concerns and subsequent modification thereof in order to arrive at a safe and cost-effective operation.

\subsection{Rock mass assessment}

A concern is the evaluation of RQD for weak rock masses which requires a definition and interpretation for sound core. The International Society for Rock Mechanics (1978) definition: "Pieces of sound core over 
$10 \mathrm{~cm}$ long that are expressed as a percentage of the length drilled." This is further defined by Deere and Deere (1988): "to only incorporate 'good' rock recovered from an interval of a borehole and not to include problematic rock that is highly weathered, soft, fractured, sheared and jointed and counted against the rock mass". The International Society for Rock Mechanics further identifies material that is obviously weaker than the surrounding rock, such as over consolidated gouge is discounted, as it is only able to be recovered by advanced drilling techniques. The author incorporates the above augmented by weak rock mass operations within this database to arrive at the following, as detailed in Milne et al. 1998. In practice, a high RQD value does not always translate to high quality rock. It is possible to log $1.5 \mathrm{~m}$ of intact clay gouge and describe it as having 100\% RQD. This may be true based on the original definition of RQD but is very misleading and gives the impression of competent rock. A parameter called handled RQD (HRQD) was introduced (Robertson 1988). HRQD (Figure 15) is measured in the same way as RQD, after the core has been firmly handled in an attempt to break the core into smaller fragments. During handling, the core is firmly twisted and bent but without substantial force or the use of any tools. This attempts to quantify sound core.
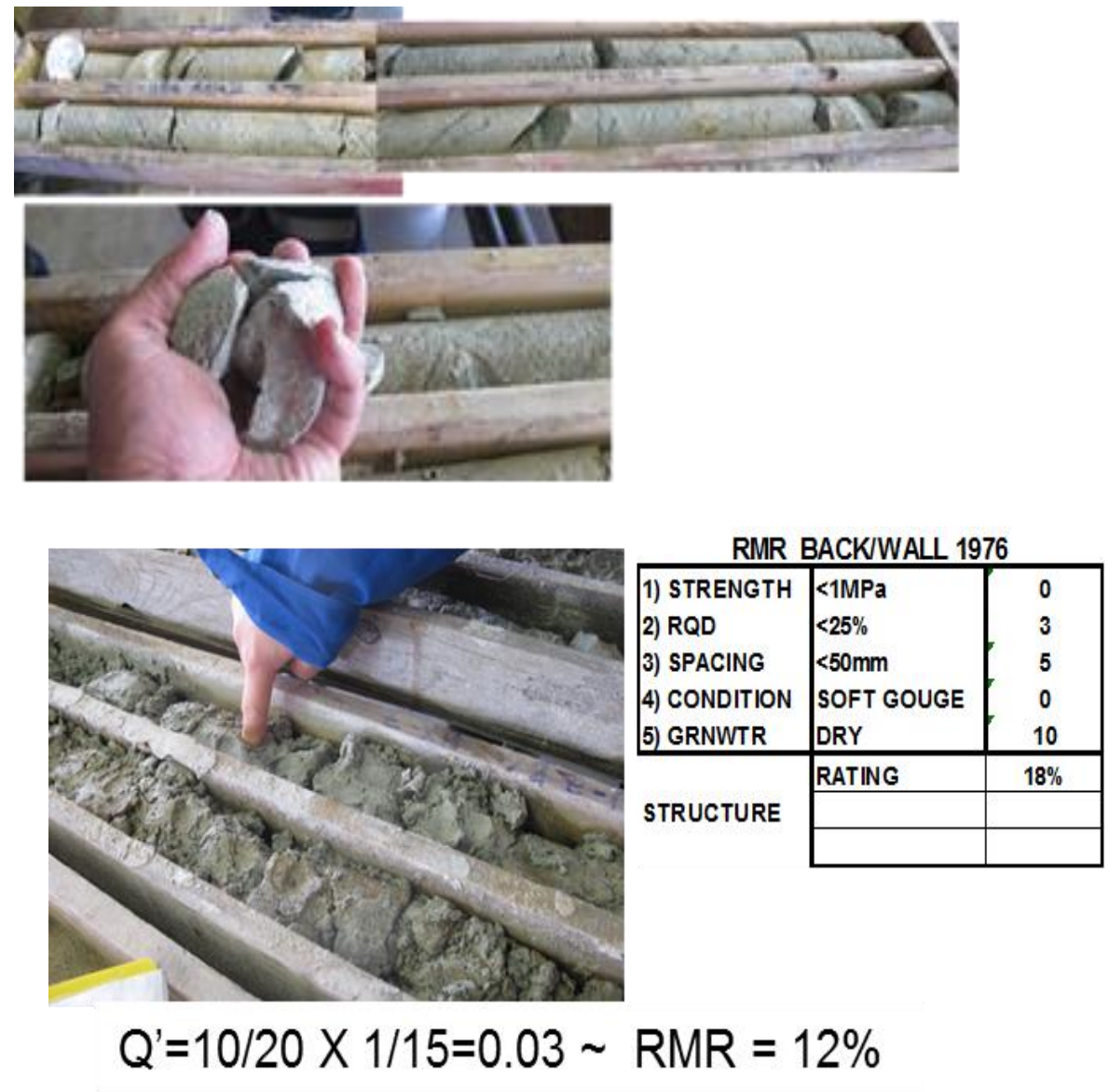

Figure 15 Handled RQD

\subsection{Underhand cut-and-fill}

A major focus of study at UBC is the development of design guidelines for mining under fill. It incorporates empirical data along with analytical assessments to arrive at design relationships that enable one to understand the overall failure mechanism and extend upon the existing state of knowledge in sill mat design (Pakalnis et al. 2006). Figure 16 and Table 5 relates the database of underhand mining operations with vertical sidewalls with a FS of 2.0. The chart is based on flexural instability employing fixed beam analysis with surcharge loading. The strengths in practice were generally lower than strengths dictated by the analytical method and this could be due to QA/QC, confinement/other. The relationship found between tensile and UCS for consolidated paste was well in excess of 0.1 UCS which has been employed historically 
in the literature which indicates that the sill mat is much stronger than assumed (Hughes 2014). This is shown in Figure 17 whereby tensile testing at Stillwater Mine cemented paste cylinders indicated a tensile strength $\sim 0.22$ of the UCS and where measured stable spans were plotted against UCS and related to the best fit UCS derived beamed theory estimate. It showed that the 0.1 UCS derived tensile strength greatly underestimated the beam stability.

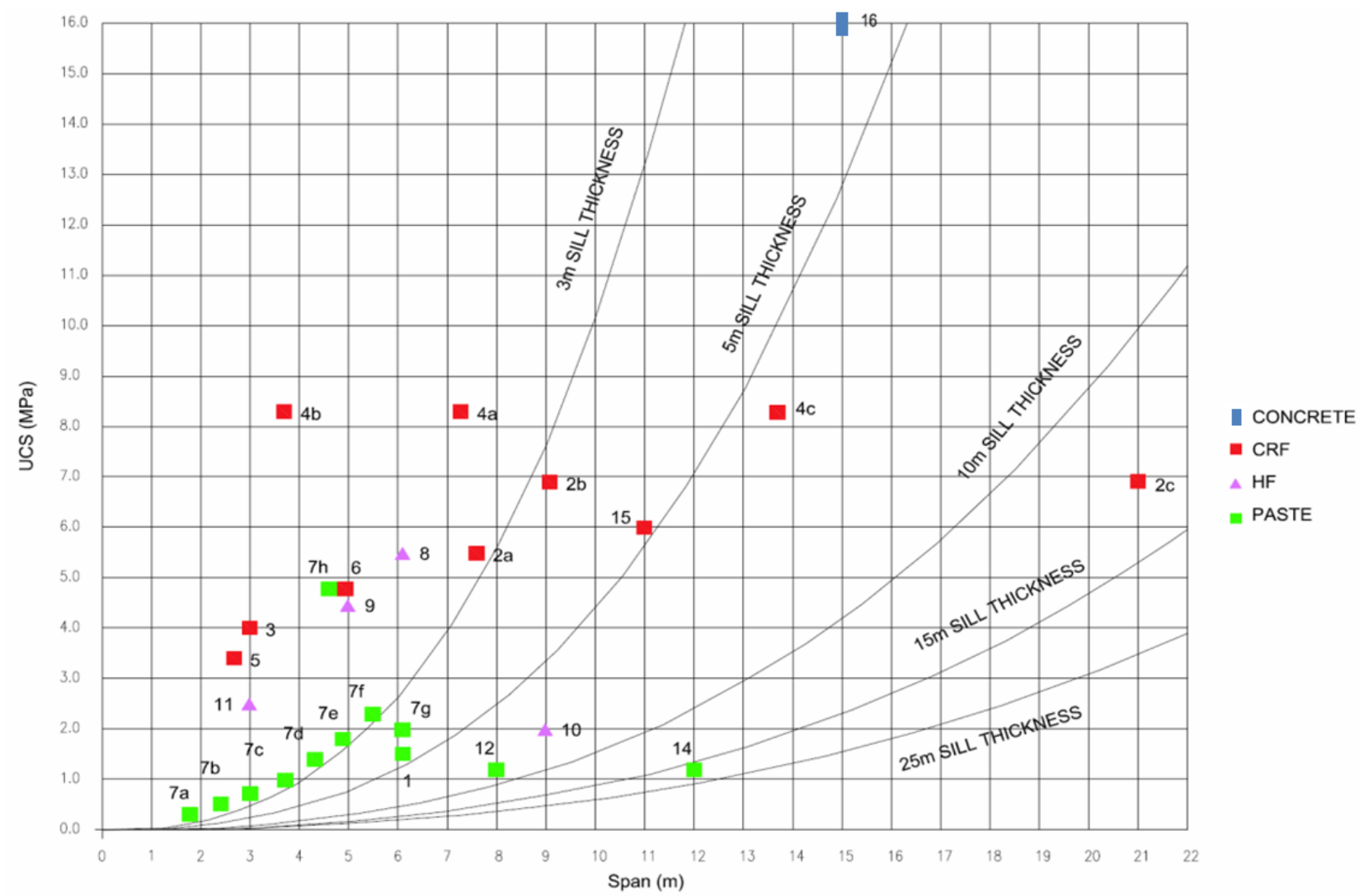

Figure 16 Stability chart for the design of undercut sills with vertical sidewalls with a FS of 2. Chart is based upon fixed beam bending failure with surcharge 
Table 5 Underhand cut-and-fill database

\begin{tabular}{|c|c|c|c|c|c|c|c|}
\hline & MINE & $\%$ CEMENT & $\begin{array}{c}\text { SPAN } \\
(\mathrm{m})\end{array}$ & $\begin{array}{l}\text { SILL THICKNESS } \\
(\mathrm{m})\end{array}$ & $\begin{array}{c}\text { UCS } \\
(\mathrm{MPa})\end{array}$ & COMMENTS & $\begin{array}{l}\text { REASON } \\
\text { UNDER FILL }\end{array}$ \\
\hline 1 & RED LAKE MINE & 10 & 6.1 & $\begin{array}{c}3 \\
(\sim 0.6 \mathrm{~m} \text { gap }) \\
\end{array}$ & 1.5 & $\begin{array}{c}\text { PASTE } \\
\text { DESIGN STRENGTHS GOVERN TIME } \\
\text { TO MINE UNDER(14D-28D) } \\
\end{array}$ & STRESS 2000m DEPTH \\
\hline $\begin{array}{l}2 a \\
2 b \\
2 c\end{array}$ & $\begin{array}{l}\text { ANGLOGOLD(1999 VISIT) } \\
\text { MURRAY MINE } \\
\text { (QUEENSTAKE-2004) }\end{array}$ & $\begin{array}{l}6.5 \\
8 \% \\
8 \%\end{array}$ & $\begin{array}{l}7.6 \\
9.1 \\
21\end{array}$ & $\begin{array}{l}4.6 \\
4.6 \\
4.6\end{array}$ & $\begin{array}{l}5.5 \\
6.9 \\
6.9\end{array}$ & $\begin{array}{c}\text { CRF } \\
\text { CRF DESIGN } \\
\text { MINED REMOTE - NO CAVE } \\
\text { 2" MINUS AGG } \\
\text { GO UNDER A MIN OF 14D, } \\
\text { WALL CRF 5-6\% BINDER } \\
\text { JAM TIGHT TO BACK/STEEP }\end{array}$ & WEAK RMR $25 \%+$ \\
\hline 3 & ESKAY & 7 & 3 & 3 & $4-12$ & $\begin{array}{c}\text { CRF(4MPa Design) } \\
\text { UCS is } 11 \mathrm{MPa}(28 \mathrm{Day})\end{array}$ & WEAK RMR $25 \%+$ \\
\hline $\begin{array}{l}4 a \\
4 b \\
4 c\end{array}$ & TURQUOISE RIDGE & $\begin{array}{l}9 \\
9 \\
9\end{array}$ & $\begin{array}{l}13.7 \\
3.7 \\
7.3\end{array}$ & $\begin{array}{l}4 \\
3 \\
3\end{array}$ & $\begin{array}{l}8.3 \\
8.3 \\
8.3\end{array}$ & $\begin{array}{l}\text { CRF TEST PANEL } \\
\text { CRF DRIFT \& FLLL } \\
\text { CRF PANEL }\end{array}$ & WEAK RMR $25 \%+$ \\
\hline 5 & MIDAS & 7 & 2.7 & 3 & 3.4 & CRF & WEAK RMR 25\%+ \\
\hline 6 & DEEP POST & 6.75 & 4.9 & 4.3 & 4.8 & $\begin{array}{c}\text { CRF } \\
\text { GO UNDER IN 28DAYS }\end{array}$ & WEAK RMR 25\%+ \\
\hline $\begin{array}{l}7 \mathrm{a} \\
7 \mathrm{~b} \\
7 \mathrm{c} \\
7 \mathrm{~d} \\
7 \mathrm{e} \\
7 \mathrm{f} \\
7 \mathrm{~g} \\
7 \mathrm{~h}\end{array}$ & STILLWATER - NYE & 10 & $\begin{array}{c}1.8 \\
2.4 \\
3 \\
3.7 \\
4.3 \\
4.9 \\
5.5 \\
6.1\end{array}$ & $\begin{array}{l}2.7 \\
2.7 \\
2.7 \\
2.7 \\
2.7 \\
2.7 \\
2.7 \\
2.7\end{array}$ & $\begin{array}{c}0.7 \\
0.3 \\
0.5 \\
0.7 \\
1 \\
1.4 \\
1.8 \\
2.3 \\
2.9\end{array}$ & $\begin{array}{c}\text { PASTE (FS=1.5) } \\
\text { GO UNDER IN 7DAYS-28DAYS) } \\
\text { (5\% BINDER-0.5MPa UCS 28D) } \\
\text { (7\% BINDER-0.7MPa UCS 28D) } \\
\text { (10\% BINDER-1MPa UCS 28D) } \\
\text { (12\% BINDER-1.2MPa UCS 28D) }\end{array}$ & STRESS 800m \\
\hline 8 & $\begin{array}{l}\text { MIEKLE STH } \\
\text { BARRICK }\end{array}$ & 7 & $4.6-6.1$ & 4.6 & 5.5 & CRF & WEAK RMR 25\%+ \\
\hline 9 & Gold Fields - AU & 10 & 5 & 5 & 4.45 & CRF & WEAK RMR $25 \%+$ \\
\hline 10 & $\begin{array}{l}\text { Stratoni Mine } \\
\text { TVX }\end{array}$ & 12.8 & $6-9$ & 6 & 2 & $\begin{array}{l}\text { High Density Slury } \\
\text { (78\% WT SOLIDS) }\end{array}$ & WEAK RMR 25\%+ \\
\hline 11 & Galena - Coeur de Alene & 10 & 3 & $\begin{array}{c}3 \\
\text { (includes } 0.9 \mathrm{~m} \text { air gap) }\end{array}$ & 2.5 & $\begin{array}{l}\text { 10\% Cemented Hydraulic Fill } \\
\text { (73-75\% Wt Solids) } \\
\text { (UCS atter } 7 \text { days) }\end{array}$ & STRESS 1000m DEPTH \\
\hline 12 & $\begin{array}{l}\text { Lucky Friday - Hecla } \\
\text { (Gold Hunter) }\end{array}$ & 8 & $2.4-4.6$ & $\begin{array}{c}3 \\
\text { (includes } 0.6 \mathrm{~m} \text { air gap) }\end{array}$ & 4.8 & $\begin{array}{c}\text { GO UNDER IN } 3 \text { DAYS(2.4MPa UCS) } \\
\text { 8\% Paste(COARSE TAlLS) } \\
\text { (no free water) }\end{array}$ & STRESS 2000m DEPTH \\
\hline 13 & $\begin{array}{c}\text { Newcrest } \\
\text { (Kencana Mine }\end{array}$ & $\begin{array}{c}12-24 \\
\text { vs dry tuff }\end{array}$ & $6-8$ & 5 & $1.2-1.5$ & $\begin{array}{l}\text { 1.2MPa IN BACK AND 0.5MPa IN WALLS } \\
\text { DESIGN STRENGTHS GOVERN TIME } \\
\text { TO GO UNDER PASTE 7D-28D }\end{array}$ & WEAK RMR 25\%+ \\
\hline 14 & $\begin{array}{l}\text { Lanfranchi Nickel Mines } \\
\text { (Helmuth South) }\end{array}$ & $4-8$ & $\begin{array}{l}6-12^{*} \\
\text { *inters }\end{array}$ & 5 & $1.2-2$ & $\begin{array}{c}\text { SPAN 6m UNDER PASTE } \\
\text { SPAN 12m INTERSECTIONS CABLED(6m) } \\
\text { TO GO UNDER PASTE 14D }\end{array}$ & STRESS 850m DEPTH \\
\hline 15 & $\begin{array}{l}\text { Cortez Hills } \\
\text { (Barrick) }\end{array}$ & 7.8 & $\begin{array}{l}6-11^{*} \\
*^{*} \text { inters }\end{array}$ & 4.6 & 6 & $\begin{array}{c}\text { GO UNDER IN } 28 \text { DAYS } \\
\text { SPAN IS 6m WITH 11m AT INTERSECTIONS } \\
\text { MAXIMUM TOP SIZE } 5 \mathrm{~cm}\left(2^{\prime \prime)}\right.\end{array}$ & WEAK RMR 15\%+ \\
\hline 16 & $\begin{array}{l}\text { Andaychagua Mine } \\
\text { (Volcan) }\end{array}$ & 14 & $5-15$ & 3.5 & $16+$ & $\begin{array}{c}\text { CEMENTED AGGREGATE FILL } \\
\text { SPAN IS 15m } \\
\text { AGGREGATE FILL -3/4" }\end{array}$ & WEAK RMR 15\%+ \\
\hline
\end{tabular}




\section{SIMPLE BEAM ESTIMATION OF STRENGTH/SPAN DESIGN FOR 3m THICK BEAM}

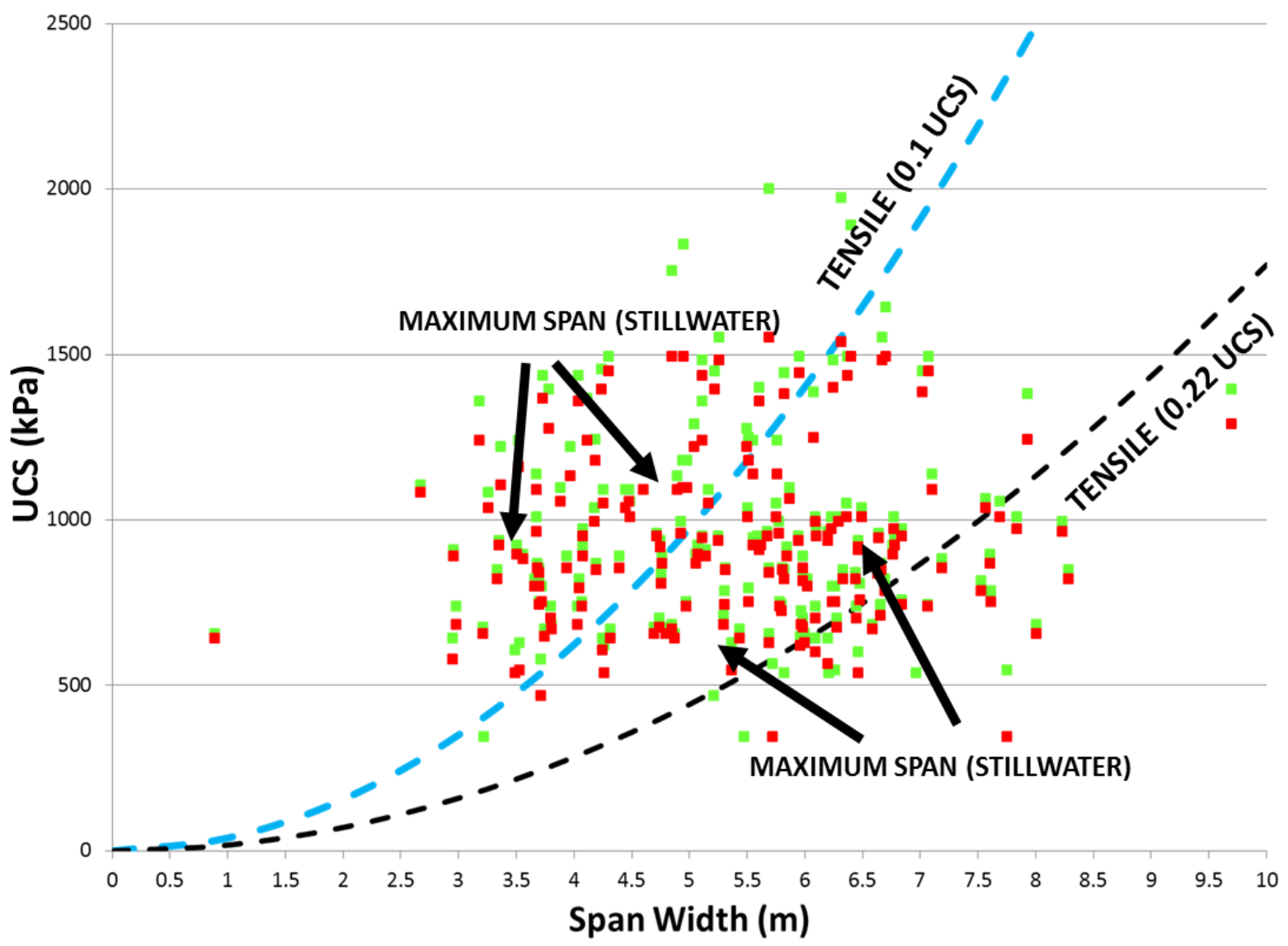

Figure 17 Stillwater Mine stable undercut paste spans versus recorded UCS with beam formulae design curves for $3 \mathrm{~m}$ thick mat

\subsection{Effect of freezing on RMR}

The Cameco operations, among others such as the Kupol Mine of Kinross, rely on frozen ground in part for stability and/or water control. A Cameco sponsored initiative and detailed by Roworth (2013) in her MSc dissertation, 'Understanding the effect of freezing on rock mass behaviour as applied to the Cigar Lake mining method', is detailed in this paper. Figure 18 shows a relationship whereby frozen versus unfrozen ground was recorded in terms of $\mathrm{RMR}_{76}$ and related to exposed span. The influence of freezing on the rock mass quality was found to be significant for very weak rocks and decreases exponentially with increasing rock mass strength. The unfrozen $\mathrm{RMR}_{76}$ for RMR under $50 \%$ upon freezing had a gain of up to 40 points, whereas unfrozen RMR greater than $50 \%$ had a frozen RMR of less than 10 point gain. Conservatively, an increase of 20 occurs, i.e. $30 \%$ unfrozen RMR is $50 \%$ frozen. 


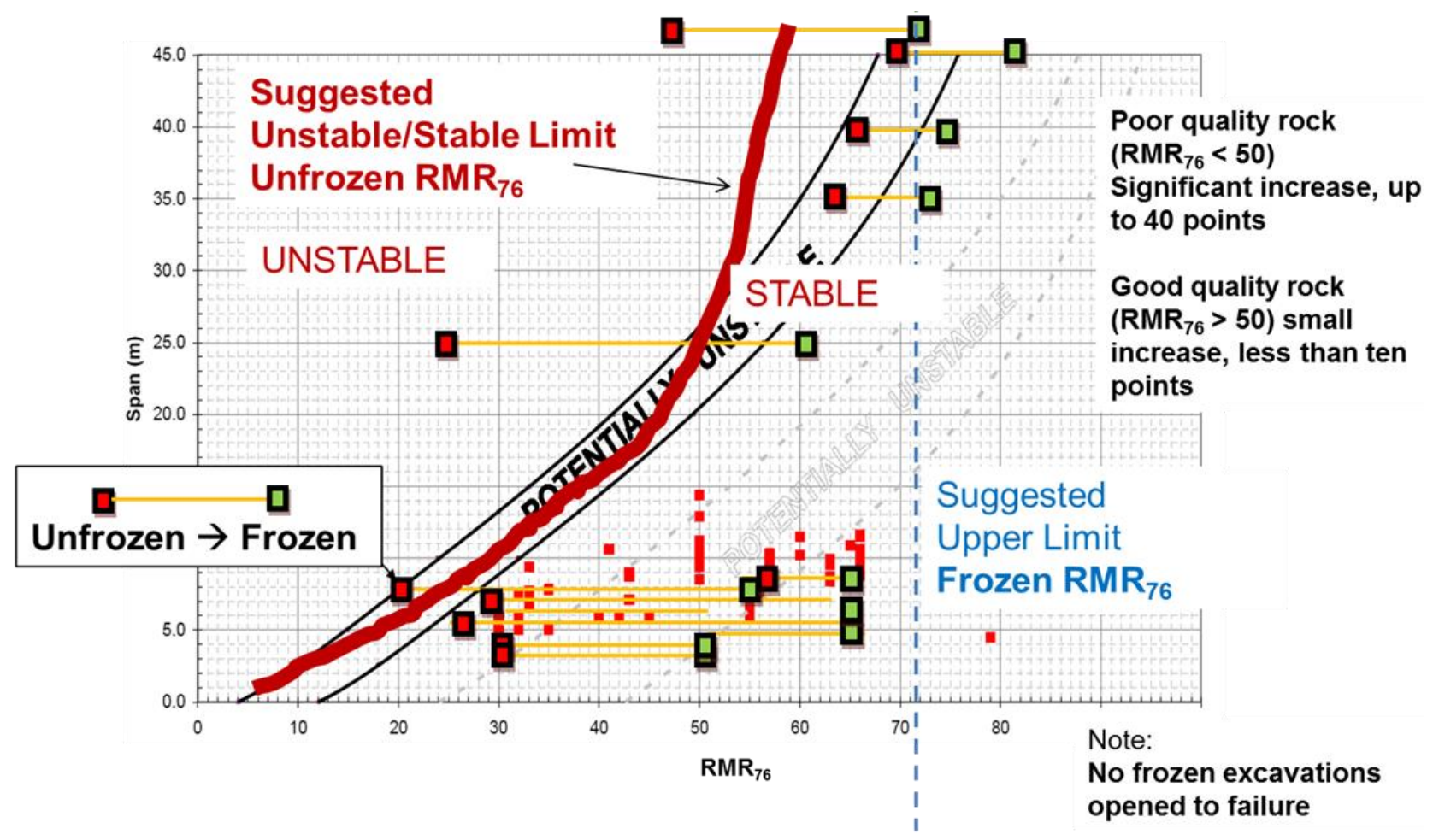

Figure 18 Effect of freezing on RMR76 (Roworth 2013)

\section{Conclusion}

The approach towards design summarised in this paper is one whereby existing databases have been calibrated to analytical and empirical approaches and modified according to observed mine behaviour. The tools have been used successfully to predict levels of dilution, pillar stability, opening stability, support requirements among factors that have been trialled in the field. The methodology towards design must identify the potential for stress, structural and rock mass instability; therefore, the design curves present only one part of the overall design process. It is critical that empirical tools be employed to predict rock response by interpolating and not extrapolating where minimal data is available. The approaches presented in this paper are to be employed as a tool for the practitioner and to augment the methodology with his/her own database and decision-making process in order to arrive at a workable solution. The relationships developed here assist the operator/engineer to identify potential concerns thereby developing a safer work environment. These design guidelines have been implemented throughout the world in association with researchers, mine engineers, operators and legislators to arrive at design methodologies based upon past practice, future implementation and assessment in order to ensure a safe and cost-effective mining operation. This seminar on empirical design is the first of many to come and allows one to define concerns, find solutions and discuss similar problems.

\section{Acknowledgement}

The students, the mines and colleagues who have contributed to the knowledge base.

\section{References}

Beauchamp, L 2006, Ground support manual, Mines and Aggregates Safety and Health Association, North Bay, ON.

Bieniawski, ZT 1976, 'Rock mass classification in rock engineering', in ZT Bieniawski (ed.), Exploration for Rock Engineering: Proceedings of the Symposium on Exploration for Rock Engineering, A.A. Balkema, Lisse, pp. 97-106.

Brady, T, Martin, L \& Pakalnis, R 2005, 'Empirical approaches for opening design in weak rock masses', Mining Technology, vol. 114, no. 2, pp. 13-20.

Caceres, C 2011, 'Quantifying the effect of rock mass quality on peak particle velocity for underground drift development' PhD thesis, University of British Columbia. 
Clark, L 1998, 'Minimizing dilution in open stope mining with focus on stope design and narrow vein longhole blasting' Master of Science thesis, University of British Columbia.

Deere, DU \& Deere, DW 1988, 'The rock quality designation (RQD) index in practice', in I Kirkaldie (ed.), Rock classification systems for engineering purposes, American Society for Testing and Materials, Ann Arbor, MI, pp. 91-101.

Grimstad, E \& Barton, N 1993, 'Updating the Q-system for NMT', in C Kompen, SL Opsahl \& SL Berg (eds), Proceedings of the International Symposium on Sprayed Concrete, Norwegian Concrete Association, $21 \mathrm{p}$.

Hughes, P 2014, 'Underhand cut and fill cemented paste backfill sill beams' PhD thesis, University of British Columbia.

International Society for Rock Mechanics 1978, 'Commission on standardization of laboratory and field tests: suggested methods for the quantitative description of discontinuities in rock masses', International Journal of Rock Mechanics and Mining Sciences and Geomechanics Abstracts, vol. 15, pp. 319-368.

Lang, B 1994, 'Span design for entry type excavations' Master of Science thesis, University of British Columbia.

Laubscher, DH 1977, 'Geomechanics classification of jointed rock masses - mining applications', Transactions of the Institute of Mining and Metallurgy, vol. 86, pp. 1-8.

Lunder, P 1994, 'Hard rock pillar strength estimation: an applied empirical approach' Master of Science thesis, University of British Columbia.

MacLaughlin, MM, Pakalnis, R \& Brady, TM 2005, 'A distinct element parametric study of failure modes around an underground opening in rock masses of varying quality', Proceedings of the 40th US Symposium on Rock Mechanics, American Rock Mechanics Association, Minneapolis, $10 \mathrm{p}$.

Mathews, KE, Hoek, E, Wyllie, DC \& Stewart, S 1981, Prediction of stable excavation spans for mining at depths below 1,000 metres in hard rock / Golder Associates, CANMET Library \& Documentation Services Division, Vancouver.

Nickson, S 1992, 'Cable support guidelines for underground hard rock mine operations' Master of Science thesis, University of British Columbia.

Pakalnis, R 2002, 'Empirical design methods-UBC Geo-mechanics update', in R Hammah, W Bawden, J Curran \& M Telesnicki (eds), Proceedings of the 5th North American Rock Mechanics Symposium and the 17th Tunnelling Association of Canada Conference (NARMS-TAC 2002), Mining and tunneling innovation and opportunity, University of Toronto, Toronto, Canada, $12 \mathrm{p}$.

Pakalnis, R 2008, 'Methodology towards ground support', Strategic versus tactical approaches in mining, Quebec, Canada, University of Laval, ACG, University of Witwatersrand, $12 \mathrm{p}$.

Pakalnis, R, Brady, T, Blake, W \& MacLaughlin, M 2006, 'Design spans - underhand cut and fill mining', Bulletin of the Canadian Institute of Mining and Metallurgy, vol. 99, no. 1094, 7 p.

Pakalnis, R, Brady, T, Hughes, P \& McLaughlin, M 2007, 'Design guidelines for underground mining operations in weak rock masses', Proceedings of the 1st Canada-US Rock Mechanics Symposium - International Workshop on Rock Mass Classification in Underground Mining, National Institute for Occupational Safety and Health, Atlanta, GA, 12 p.

Pakalnis, R, Roworth, M, Caceres, C, Martin, L, Seymour, B \& Lourence, P 2010, 'Ground support methodology employing shotcrete for underground mines', Proceedings of the SME Annual Meeting and Exhibit, Society for Mining, Metallurgy \& Exploration, Englewood, CO, preprint no. 10-013, pp. 55-58.

Potvin, Y 1988, 'Empirical open stope design in Canada' PhD thesis, University of British Columbia.

Robertson, AM 1988, 'Estimating weak rock strength', Proceedings of the SME Annual Meeting, Society for Mining, Metallurgy \& Exploration, Englewood, CO, preprint no. 88-145, 5 p.

Rocscience 2008, Unwedge software package, https://www.rocscience.com/rocscience/products/unwedge

Roworth, M 2013, 'Understanding the effect of freezing on rock mass behaviour as applied to the cigar lake mining method' Master of Science thesis, University of British Columbia.

Wang, J, Pakalnis, R, Milne, D \& Lang, B 2000, 'Empirical underground entry-type excavation span design modification', Proceedings of the 53rd Annual Conference of the Canadian Geotechnical Society, The Canadian Geotechnical Society, Richmond, BC. 